\title{
Assessment of the Perceptions of Pre-service Teachers towards Practical Work in the Context of Scientific-technological Literacy
}

\author{
L. Aragón ${ }^{a^{*} \mathbb{C}}$ \\ ${ }^{a}$ Faculty of Education, Universidad de Cádiz, Puerto Real, 11519 Cádiz, Spain.
}

Received 12 July 2020; Revised 23 August 2020; Accepted 28 August 2020; Published 01 September 2020

\begin{abstract}
This research aims to analyze the perceptions of future preschool teachers towards the application of practical work. This study is part of a more comprehensive teaching innovation project, which aims to contribute to the scientific and technological literacy of teachers in initial training. Three practical activities were designed from the topic Didáctica del Medio Natural at the University of Cádiz (Spain) and implemented during the 2018-2019 year. After their completion, a questionnaire was provided of three closed questions Likert type with five levels. The student's answers were analysed from a quantitative approach taking into account aspects: (1) Usefulness for professional training; (2) Degree of satisfaction with contents; and (3) Degree of utility for your future teaching career. Results indicate that students, in general, were very satisfied with the development of the practical work designed. However, their opinions varied when they considered their usefulness for future teaching work. In conclusion, results indicate that practical work allows future teachers to increase their interest in science. However, it can be advised of the necessity to look for spaces to be able to discuss the learning acquired and to be able to adapt these practices to the children's classroom to consider their didactic potential.
\end{abstract}

Keywords: Environmental Science; Scientific-technological Literacy; Practical Work; Teacher Initial Training.

\section{Introduction}

The current vision of science teaching and learning is directed towards a goal based on achieving scientific and technological literacy (STS) for all people [1]. This goal is, according to Solbes and Vilches (1997) [2], a science education that contributes to forming citizens, and in their case, future scientists, capable of developing in their immediate environment and being aware of the role that science plays in their personal and professional lives. In short, citizens whose scientific training allows them to reflect, take decisions, and act on the issues related to science and technology that affect them in their daily lives.

To this end, Hodson (1994) [3] points out that science education should include three aspects: 1) learning about science, acquiring and developing theoretical and conceptual knowledge; 2) learning about the nature of science $(\mathrm{NdC})$. Referred to the understanding of how scientific research is conducted, the different types of experience claims that scientists make, how scientists' reasons for linking data and explanation, or, for example, the role of the scientific community in testing knowledge [4]. Finally, 3) learning to do science, which refers to the practice of science, developing technical knowledge about scientific research and participating in problem-solving. Other authors such as Grilli-Silva (2018) [5] argued that teaching and learning science aims at the introduction of students into the scientific method used to build its knowledge.

* Corresponding author: lourdes.aragon@uca.es

doi http://dx.doi.org/10.28991/HIJ-2020-01-03-04

$>$ This is an open access article under the CC-BY license (https://creativecommons.org/licenses/by/4.0/).

(C) Authors retain all copyrights. 
From this approach, practical work is conceived as a type of activity that is essential for learning science, but in which the student is required to know what he or she is doing [6]. In many cases, the practical work is little related to the didactic objectives pursued and focuses mainly on developing manipulative skills, rather than on solving problems and contributing to systemic thinking [7].

In this study, practical work is defined, according to the considerations established by Millar (2004) [4], as any teaching and learning activity that involves, at a given time, students in the observation or manipulation of objects and materials they are studying. It is not only restricted to laboratory work, since observing and manipulating objects can be done in other spaces, both in a school laboratory and in an out-of-school environment, the so-called field trips [4, 8]. Brink (2020) [9] argues that practical works can be very diverse and cover a wide variety of objectives. This study range from experiences, which make the student familiar with the case of study, to illustrative experiments, which allow us to show the relationship between variables and practical skills. All these activities help in the learning process of new skills which are relevant in science research contexts, allowing the students to play the role of school scientists [6]. An observation that is considered fundamental to rethink and design appropriate strategies for carrying out science in schools.

There is some controversy in the literature about the effectiveness of practical work as a teaching and learning strategy in school science. Abrahams \& Millar (2008) [10] analysed the effectiveness of practical work in secondary school students. These authors state that in the short term, practical work seems to be effective in achieving actions involving the use of physical objects. Still, on the contrary, it is less effective in developing scientific ideas to guide students' activities or to allow them to reflect on the data collected. In this respect, Izquierdo et al. (1999) [6], argue that one possible reason why practical work is not sufficient is that school experiments are designed with the same reference as scientists. These authors consider that teachers should instead create scripts to learn specific aspects of science in the setting in which they occur, i.e. in the school context, which is very different from the context in which scientific research is carried out.

As for the emotional and affective aspect linked to the practical work, there are also contradictory results; on the one hand, practical work is proposed as an adequate strategy for increasing motivation, stimulation and development of scientific attitudes in students, among other skills [11, 12]. However, a study carried out by Abrahams (2009) [13] in the context of secondary school pupils, indicates that practical work generates a short-term commitment, but in the long term, it proves to be ineffective in developing lasting motivation to study science.

Regarding teachers' perceptions of practical work, the literature demonstrates that, in general, future teachers and current teachers, value practical activities positively, mainly because they allow to relate theory with practice. However, they do not seem to consider so much the impact of this type of activities to cover conceptual learning or as an introduction to scientific work [14]. And in many cases, fewer hours are spent on these activities at the curriculum level [6].

On the other hand, another problem is that in general, future teachers show negative attitudes and emotions towards teaching science, considering it tedious, complicated and far from daily life. Several studies [15, 16] reveal a poor attitude by future teachers towards the learning of science. Taking into account that the affective component and attitude are considered as factors that play a pivotal role in learning and teaching science. According to Mellado et al. (2014) [17], negative emotions can act as real barriers students, as well as for educators [18] in a learning process. Furthermore, it is not only the lack of interest from teachers regarding science, but also the fact that, as shown by several research studies, current teachers have a low profile in science [19, 20]. This fact appears as one of the main obstacles when it comes to addressing science at school [21]. Besides, studies make evident the low presence, in preparatory school, of science teaching activities, focused on the scientific methodology or the argumentation [22].

Correspondingly, teachers who dedicate themselves to initial teacher training have a great challenge ahead. For this reason, it is necessary to design educational proposals able to foster the interest of our students in science while favouring the development of positive attitudes towards this subject. Based on this statement we believe that it is necessary to continue to study these aspects in-depth, on the one hand, the perceptions that future teachers have towards practical work because these can have an impact on their future teaching activity. On the other hand, because these studies can provide useful information when it comes to improving the design of the practical work itself and implementing didactic proposals with the aim of training teachers from the perspective of the STS.

\subsection{Research Aim}

During several academic courses, academic staff in the Department of Didactics and Experimental Sciences of the Faculty of Education Sciences of the University of Cádiz (Spain) have observed that students have a low profile and adverse attitudes towards science, considering this school subject difficult and tedious. There is a critical disconnection perceived, which we think can have an impact on how our students, future teachers, design, and develop practice work in children's classrooms. In this context, during the academic year 2018-2019, an innovative proposal 
was designed. Four practical sessions were designed under the topic Didáctica del Medio Natural (DMN), based on both laboratory and field trip. Practical work was implemented to increase the interest and to develop positive students' attitudes towards science to contribute to the STS of our students. The main research question in this study is: How do future preschool teachers perceive practical work for their initial and future training? Therefore, the paper aimed at analysing students' perceptions after four practical sessions. In this research, the opinion from students was analysed based on three aspects: 1) Usefulness for professional training; (2) Degree of satisfaction with contents; and (3) Degree of utility for the future teaching profession.

\section{Research Methodology}

\subsection{Population and a Sample}

This research focused on the topic Didáctica del Medio Natural, at the University of Cadiz (Spain), in the 3rd year of a degree programme leading to Early Childhood Education. The topic is mandatory, and it is the only one covering experimental sciences teaching during the degree leading programme. The topic covers the first semester and has a duration of 15 weeks. The practical works were designed and distributed in four sessions. Each session has one hour and a half of time, and it includes individual activities, alternating between small groups and large groups. Thus, students were generally grouped into work teams formed by 5-6 members each. A total of 56 students, 7 men and 49 women, aged between 19 and 41 years, have participated in the study.

\subsection{Teaching Intervention}

The practical works were implemented simultaneously in tutorial sessions. The contents that were introduced in those sessions correspond to the block 1 of the topic which is centred on the question: why to teach and learn science, the very concept of STS, and the need to train future citizens with a critical sense, and capable of making technoscientific decisions. Students are discussed how science can contribute to understanding advertising or deception, through pseudoscience [23]. We also work on how science allows decisions to be made and participation in society [24].

At the same time, four practical sessions were held to complement the content worked on in the theoretical sessions described above. In practicum 1 (P1) under the name 'Laboratory as a learning space', the students, organised in workgroups, had to complete the form given by the teacher. The goal of this exercise is to recognise different spaces of the laboratory, propose safety standards through the creation of a Decalogue, recognise labels of substance indicators present in the laboratory and know instruments and devices to operate with measurements and calculations of temperature, volume and mass. In practicum 2 (P2) under the name 'Do we know what we eat?' students had to design and carry out short research about the presence of starch in food (bread, potato, apple and three different brands of ham). P2 was divided into two parts: First, practical work was more illustrative, and groups had to know and apply the technique of Lugol; in a second moment, groups had to strictly design a small investigation to determine the presence or absence of starch in certain foods. Finally, the different groups had to share their results, discuss with the entire class and expose, reflect and draw conclusions on how science helps us to be more critical. This action allowed $\mathrm{P} 2$ to be related to the science content of the teaching and learning purposes covered by the topic in the block 1, within the context of a collaborative extensive group session (Figures $1 \mathrm{~A}$ and 1B).
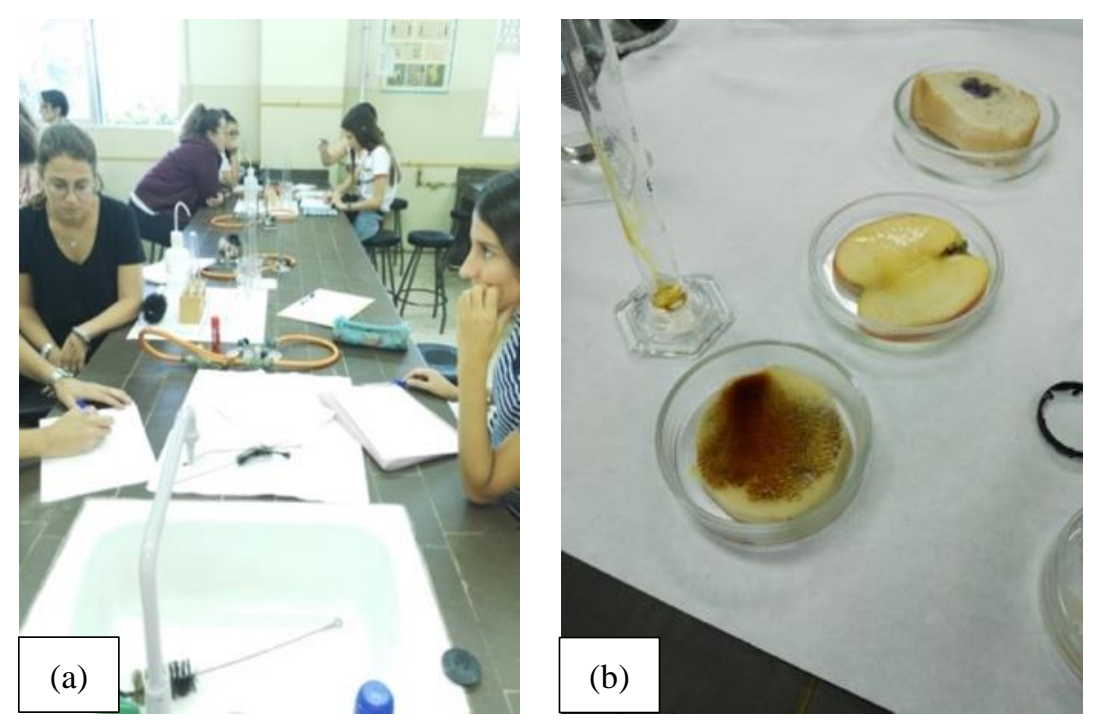

Figure 1. a) Practicum 1. Laboratory as a learning space: basic safety standards and laboratory equipment; b) Practicum 2. Do we know what we eat? Research design based on the topic of starch content in foods 
Practicum 3 (P3) was divided into two different sessions. First, ideas about the concept of life and dead matter were explored by using a questionnaire. Complementarily, fieldwork was programmed in the area that surrounds the Faculty - the natural park of 'Los Toruños'. A circuit of 30 minutes route was established. During this time, the teams had to collect elements that they considered part of the natural environment. Back in the laboratory, students had to identify the features and classify them as living and dead matter. In the second session, the work teams had to build a dichotomous key using A3 format. To do this, the teacher made a brief explanation about the use of dichotomous keys to identify and classify organisms or objects. A dichotomous key adapted to the stage of children, by López and De la Cruz (2016) [25], was shown as an example. The key is organised into dichotomies (sometimes trichotomies) or dilemmas, i.e., pairs of opposing statements.

Students, by teams, had to design a dichotomous key to classify the elements collected in the previous session. Each group presented its dichotomous key to the rest of the class, and a discussion was carried out on the features that exist in the natural environment, bearing in mind the dichotomy of living and dead matter (Figures 2A and 2B). When designing the dichotomous key, the students had particular difficulties in assigning characteristics that allowed them to classify the collected elements. A clear example of this was the identification of components such as hardness, colour or textures for the inert matter. They also presented doubts between the inert concepts and "death."
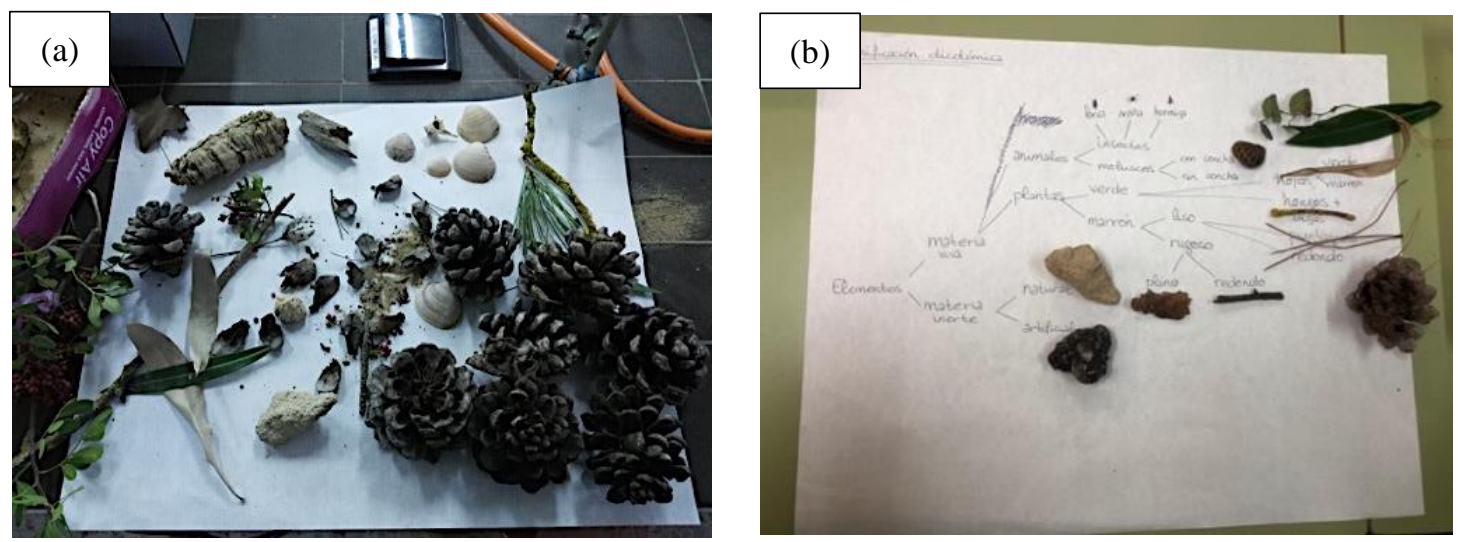

Figure 2. Practicum 3. What is alive? What are the components that make the natural environment? a) Samples collected during fieldwork in the natural park 'Los Toruños'; b) Design of a dichotomous key using collected samples from the natural environment

\subsection{Data Collection Instrument}

Once each practical work was finished (P1, P2 and P3), students, individually, had to submit a field diary and answer a specific survey for each practical work. The surveys were designed following the work of Dávila et al. (2015) [26]. Questions in every survey were adapted based on the objectives settled for each practical work. The surveys shared questions aiming at understanding the opinion of the students in every aspect. Each form contained three questions to address the case of study adequately. The questions are closed, and they use a Likert scale that offers the student the possibility to choose between four different levels of agreement or disagreement. Figure 3 shows a flowchart that summarises the research process.

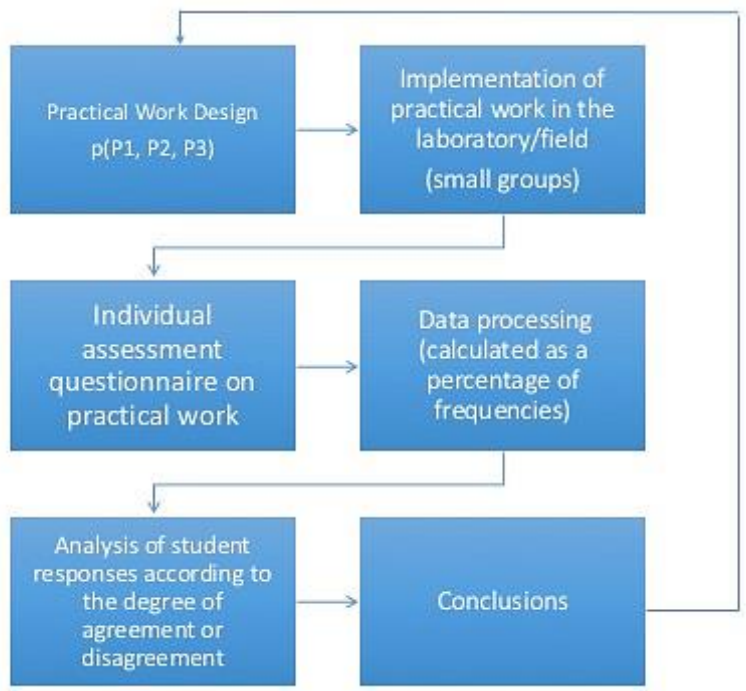

Figure 3. Flowchart about research process 


\subsection{Data Analysis Procedures}

The data collected were processed by quantitative analysis, counting absolute frequency that was performed with SPSS 21 software (mac version). A comparative analysis was carried out based on the percentages of frequencies for the three aspects considered for each practical work, designed and implemented for teaching and learning the topic DMN.

\section{Findings and Discussion}

The results obtained from the analysis of the survey answers are shown in Table 1. Regarding usefulness, results indicate that students show agreement, perceiving all the three activities as positive. However, according to the obtained data, some practical work received better scores than others. P1 shows that $61 \%(\mathrm{~N}=51)$ of the students considered that they were totally in agreement with the usefulness of the activity for professional training purposes; instead, P3 and P2 received $43 \%$ and $59 \%$, respectively.

P1 was the activity most valued by the students, due to their training as teachers and the called 'novelty factor' [27, 28]. This term refers to field trips but can be extended to practical laboratory work since it relates to three aspects: 1 . Cognitive (concepts and skills that students should handle during the activity); 2. Geographical (the place where the activity will take place, or the workspace, the laboratory in our case); 3. Psychological (the gap between expectations and the reality that students find during practical work). In this sense, the fact of using these resources so scarcely during their academic training makes the novelty factor increase. This fact could be related to a higher assessment and degree of satisfaction by students, not considering other methodological aspects.

Table 1. Survey results. Perceptions from students after the practical work applied in DMN topic during the academic year 2018-2019 (\%)

\begin{tabular}{|c|c|c|c|}
\hline (1) Useful for professional training & $P 1(N=51)$ & $P 2(N=51)$ & $\mathrm{P3}(\mathrm{N}=56)$ \\
\hline Totally agree & $61 \%$ & $43 \%$ & $59 \%$ \\
\hline Agree & $38 \%$ & $55 \%$ & $41 \%$ \\
\hline Disagree & 0 & 0 & 0 \\
\hline Totally disagree & 0 & 0 & 0 \\
\hline Does not answer & $1 \%$ & $2 \%$ & 0 \\
\hline (2) Degree of satisfaction of contents & $P 1(N=51)$ & $\mathbf{P 2}(\mathbf{N}=51)$ & P3 $(\mathrm{N}=56)$ \\
\hline Totally agree & $29 \%$ & $55 \%$ & $38 \%$ \\
\hline Agree & $65 \%$ & $41 \%$ & $62 \%$ \\
\hline Disagree & $4 \%$ & $4 \%$ & 0 \\
\hline Totally disagree & 0 & 0 & 0 \\
\hline Does not answer & $2 \%$ & 0 & 0 \\
\hline (3) Utility for your future teaching work & $P 1(N=51)$ & $\mathbf{P 2}(\mathrm{N}=51)$ & $P 3(\mathrm{~N}=56)$ \\
\hline Totally agree & $53 \%$ & $53 \%$ & $36 \%$ \\
\hline Agree & $45 \%$ & $47 \%$ & $53 \%$ \\
\hline Disagree & 0 & 0 & $11 \%$ \\
\hline Totally disagree & 0 & 0 & 0 \\
\hline Does not answer & $2 \%$ & 0 & 0 \\
\hline
\end{tabular}

The degree of satisfaction with the contents also obtained positive reactions, since the majority of the students stated that they agree or totally agree with each practical work and in no case were negative responses received. Despite the important difference between the experiences from P1, with a $65 \%$ of the acceptance, against P2, with $41 \%$, and P3, with $62 \%$ there are still aspects to highlight from each practice. P2 got a higher percentage of students who are totally satisfied with its contents than P1 and P3 did. P2 was a practice that involved instruments manipulation and specific staining techniques to assess the presence of starch in food. This practice related to food which is a subject of interest and close to students. The other two practices a priori do not have such a close relationship with their daily lives.

Consequently, this could be the cause of the higher percentage of students who stated to be totally satisfied with P2. Finally, regarding the third aspect analysed in this research - the utility of the practice for your future teaching work - students rated P1 and P2 more positively than P3. Students showed a lower level of agreement with P3 (only $11 \%$ agreed) probably due to the difficulty they felt when they were asked to design a dichotomy key. 
According to the results obtained, students seem to value the usefulness of the practices for their future, as soon as they become classroom professionals, consistently with the degree of difficulty that they experienced when performing them. These results are consistent with those that emerged from other studies carried out with future primary school teachers when assessing the use of analogical resources and their transference into the primary school [29, 30]. As a conclusion, it can be said that the use of particular resources is complex or challenging for some future teachers. They rated lower the activities that they felt more complicated, thinking that when they have to transfer them to the classroom, their future students will feel the same difficulty. Students did not consider the possibility of adapting the resources to be used by children of 3 to 6 years old, neither of adapting them to the needs of prospective teachers. Besides, they did not attend to the didactic potential that this resource may offer when one wants to teach specific science content.

\section{Conclusions}

In general, the results show a very positive reaction of prospective teachers to practical work, as they believe that it will work as a good mediator in the learning process. However, further investigation needs to be undertaken into students' perceptions of practical work, using other instruments of qualitative analysis. An excellent example in this regard is the use of laboratory notebooks or individual interviews, which can help to develop more insights about student teachers' perceptions. In general, practical work designed for this study seems to have awoken students' interest in science whilst developing other essential skills that are relevant to scientific research. This result has important implications in the short term, given that prospective teachers should be able to transfer these practices to their future students. The preparatory school is a fundamental educational stage in children's education. One of the main objectives to be attained in this period has to do with initiating students into scientific practices. These practices involve the development of scientific skills such as observation, variable manipulation, or hypothesis formulation. To do this, it is necessary for teachers to be able to not only transmit scientific knowledge but also promote the development of research skills.

As a consequence, teachers need to be able to propose understandable and searchable questions to children of early ages as a means to lead them to investigate their natural environment and to develop an understanding of the milieu that surrounds them [31]. Nevertheless, a fundamental aspect of improving the effectiveness of practical work is to incorporate spaces for reflection and explicit teaching strategies into the classroom to help students establish relationships between the practical work carried out and the scientific content and ideas that are intended to be achieved [10]. On the other hand, to be able to awaken an interest in science in the long term and go beyond pure activism, In short, practical work has an essential role in the teaching and learning of science, but its implementation must be mediated. An alternative, according to Izquierdo et al. (1999) [6], could be through questions of the type "what I have there, what I do, what is happening, how it is happening," which would help students to make sense of their observations and facts, with a model being necessary as a frame of reference.

Besides, another valuable aspect to be pursued in future research would be to monitor prospective teachers to find out how they can adapt their practices in schools during their teaching practice. Besides, it should be assessed how the end of undergraduate programme projects impacts on their interest in science. Carrying out these studies would be vital because they involve actions that could lead to an increase in the number of prospective teachers who intend to teach science at the primary level through practical work. Also, it could offer relevant information on how to train future teachers in case the research concludes shows that participants demonstrate a real interest in science.

From the initial teacher education perspective, it is necessary to continue the task of planning and designing teaching proposals. This should integrate practical work into classroom strategies to promote scientific research. And it is recommended to be done by applying small, but real, research to solve meaningful questions and problems from the participants' point of view. Practices of this type also integrate modelling and argumentation and would allow working with the three essential components of scientific competence.

\section{Declaration of Competing Interest}

The authors declare that they have no known competing financial interests or personal relationships that could have appeared to influence the work reported in this paper.

\section{References}

[1] Acevedo Díaz, J. (2017). Reflections on the purposes of science teaching: scientific education for citizens. Eureka Magazine on Teaching and Dissemination of Sciences, 1(1), 3-16.

[2] Solbes, J., \& Vilches, A. (1997). STS interactions and the teaching of physics and chemistry. Science education, 81(4), 377-386. doi:10.1002/(SICI)1098-237X(199707)81:4<377::AID-SCE1>3.0.CO;2-9.

[3] Hodson, D. (1994). Towards a more critical approach to laboratory work. Science Teaching: Journal of Research and Didactic Experiences, 12(3), 299-313. 
[4] Millar, R. (2004). The role of practical work in the teaching and learning of science. Paper prepared for the Committee: High School Science Laboratories: Role and Vision, National Academy of Sciences, Washington, DC, United States.

[5] Grilli Silva, J. (2018). The natural material in school biology. Ethical and didactic considerations on practical laboratory activities. Eureka Magazine on Teaching and Dissemination of Sciences, 15(1), 1-19. doi:10.25267/rev_eureka_ensen_ divulg_cienc.2018.v15.i1.1104.

[6] Izquierdo, M., Sanmartí, N., \& Espinet, M. (1999). Foundation and design of school practices of experimental sciences. Science Education, 17 (1), 45-59.

[7] Kirschner, P.A. (1992). Epistemology, Practical Work and Academic Skills in Science Education. Science \& Education 1, 273299.

[8] Sharp, J., Peacock, G., Johnsey, R., Simon, S., Smith, R., Cross, A., \& Harris, D. (2020). Primary science: teaching theory and practice. SAGE Publications, California, United States.

[9] van den Brink, M. (2020), "“Reinventing the wheel over and over again”. Organizational learning, memory and forgetting in doing diversity work", Equality, Diversity and Inclusion, 39 (4), 379-393. doi:10.1108/EDI-10-2019-0249.

[10] Abrahams, I., \& Millar, R. (2008). Does Practical Work Really Work? A study of the effectiveness of practical work as a teaching and learning method in school science. International Journal of Science Education, 30(14), 1945-1969. doi:10.1080/09500690701749305.

[11] Hodson, D. (1992). In search of a meaningful relationship: an exploration of some issues relating to integration in science and science education. International Journal of Science Education, 14(5), 541-562. doi:10.1080/0950069920140506.

[12] Trautner, M., \& Schwinger, M. (2020). Integrating the concepts self-efficacy and motivation regulation: How do self-efficacy beliefs for motivation regulation influence self-regulatory success? Learning and Individual Differences, 80, 101890. doi:10.1016/j.lindif.2020.101890.

[13] Abrahams, I. (2009). Does Practical Work Really Motivate? A study of the affective value of practical work in secondary school science. International Journal of Science Education, 31(17), 2335-2353. doi:10.1080/09500690802342836.

[14] García Barros, S., Martínez Losada, C., \& Mondelo Alonso, M. (1998). Towards the innovation of practical activities from teacher training. Science Education, 16(2), 353-366. doi:10.5565/rev/ensciencias.4138.

[15] Sahin, D., \& Yilmaz, R. M. (2020). The effect of Augmented Reality Technology on middle school students' achievements and attitudes towards science education. Computers \& Education, 144, 103710. doi:10.1016/j.compedu.2019.103710.

[16] Ocaña, M., Quijano, R., \& Toribio, M. (2013). Learn science to teach science. IX International Congress on Research in Science Didactics, Girona, Spain (9-12 September), 2545-2551.

[17] Mellado, V., Borrachero, A., Brígido, M., Melo, L., ..., Vázquez, B., Jiménez, R., \& Bermejo, M. (2014). Emotions in science teaching. Science Education, 32(3), 11-36. doi:10.5565/rev/ensciencias.1478

[18] Santmartí, N. (2001). Teaching to teach Science in Secondary: A very complicated challenge. Interuniversity Journal of Teacher Training, 40, 31-48.

[19] Abell, S. (2007). Research on science teacher knowledge. In S. Abell, \& N. Lederman (Eds.), Handbook of research on science education (pp. 1105-1149). Mahwah, NJ: Lawrence Erlbaum.

[20] Ampumuza, G. J., Okaka, W., Obanda, P. W., \& Watmon, T. B. (2020). Assessing Decentralized Contract Life Cycle Management Issues and Challenges. Journal of Human, Earth, and Future, 1(1), 20-29. doi:10.28991/hef-2020-01-01-03.

[21] Cantó, J., \& Serrano, N. (2017). What are the main problems to make science present in early childhood classrooms?: The vision of practicing teachers. X International Congress on Research in Science Didactics, Sevilla, Spain (5-8 September), 1995-2000.

[22] Giri, V., \& Paily, M. U. (2020). Effect of Scientific Argumentation on the Development of Critical Thinking. Science \& Education, 29(3), 673-690. doi:10.1007/s11191-020-00120-y

[23] Aragón, L., Jiménez-Tenorio, N., Vicente Martorell, J., \& Eugenio, M. (2021). Do the conceptions about science of future teachers' progress after the implementation of constructivist proposals for scientific literacy?, Gondola, Science Teaching and Learning, 16(1), 78-95

[24] Jiménez-Tenorio, N., Vicente Martorell, J. J., Aragón Yúñez, L., \& Oliva Martínez, J. M. (2020). Promote argumentation in science classes through a socio-scientific controversy in future teachers. Apex. Journal of Science Education, 4(1), 79-86. doi:10.17979/arec.2020.4.1.4639.

[25] López, M., \& De la Cruz, O. (2016). Collections and dichotomous keys. Classify and identify natural elements from children. Alembic Didactics of Experimental Sciences, 84, 55-60. 
[26] Dávila, M., Borrachero, A., Cañada, F., Martínez, G., \& Sánchez, J. (2015). Evolution of the emotions experienced by students of the master's degree in primary education, in the didactics of matter and energy. Eureka Magazine on Teaching and Dissemination of Sciences, 12(3), 550-564.

[27] Aguilera, D. (2018). The field trip as a didactic resource to teach science. A systematic review. Eureka Magazine on Teaching and Dissemination of Sciences, 15(3), 1-17.doi:10.25267/rev_eureka_ensen_divulg_cienc.2018.v15.i3.3103.

[28] Orion, N., \& Hofstein, A. (1994). Factors that influence learning during a scientific field trip in a natural environment. Journal of Research in Science Teaching, 31(10), 1097-1119. doi:10.1002/tea.3660311005.

[29] Aragón, L., Jiménez-Tenorio, N., \& Oliva, J. (2014). Evaluando una experiencia de formación inicial con maestros sobre el sistema Sol-Tierra desde la óptica de la modelización. Actas de los XXVI Encuentros de Didáctica de las Ciencias Experimentales, 193-200.

[30] Jiménez-Tenorio, N., Aragón, L., \& Oliva, J. (2016). Percepciones de estudiantes para maestros de Educación Primaria sobre los modelos analógicos como recurso didáctico. Enseñanza de las Ciencias, 34(3), 91-112.

[31] Caballero, A., \& Dashoush, N. (2017). Planting Deeper. Outdoor experiences challenge children's misconceptions about the needs of plants. Science and Children, 55(2), 56-61. 